\title{
SIDEBAR. The Mid-Pleistocene Enigma
}

By Heather L. Ford and Thomas B. Chalk

Variations in Earth's orbit affect incoming solar radiation and have guided past glacial-interglacial oscillations. These rhythmic changes in insolation are known as Milankovitch cycles. Approximately 900,000 years ago, Earth's climate pacemaker skipped a beat and switched from the 41,000-year obliquity (Earth's axial tilt) pacing of the Early Pleistocene to 100,000-year eccentricity (circularity of Earth's orbit around the sun) pacing of the Late Pleistocene. This glacial-tointerglacial shift, called the Mid-Pleistocene Transition (MPT), remains one of the most enduring mysteries of the Quaternary and in the field of paleoceanography. Recent reconstructions of atmospheric and oceanic processes and studies of the dynamic linkages between them have paved the way for a more detailed mechanistic understanding of this climatic transition and of Earth's climate system at large.

Advances in geochemical techniques applied to studies of ocean sediment cores recovered by scientific ocean drilling enable reconstruction of higher-resolution paleoclimatic records of atmospheric $\mathrm{CO}_{2}$, ocean remineralized carbon content, ocean circulation change, and ice volume. We now understand that the characteristic timescales of glacialinterglacial variability are primarily linked to dynamical processes modulated by the ocean and its interaction with ice sheets-in particular, we understand much more about the Southern Ocean's role in moderating Earth's climate and its characteristic beats.

The MPT occurred in at least two steps (Figures 1 and 2). The first was the "900 kyr event" around Marine Isotope Stage (MIS) 22, when the quasi-eccentricity signal emerged. The second was MIS 16 when the transition was complete. The first step had the largest impact on ocean carbon cycling and (likely) on atmospheric carbon. The Early Pleistocene had symmetrical ice age cycles and a glacial-to-interglacial atmospheric $\mathrm{CO}_{2}$ of $\sim 240-285 \mu$ atm (Yan et al., 2019, and references within). Between MIS 22 and MIS 16, there were weak interglacial and increasingly severe glacial periods. At MIS 16,

${ }^{1}$ Marine isotope stages are alternating warm and cool periods in Earth history deduced from oxygen isotope ratios of fossil benthic foraminifera shells recovered from deep-sea sediments. Even numbers represent cold glacial periods and odd numbers represent warmer interglacial periods. MIS 1 is the present day.

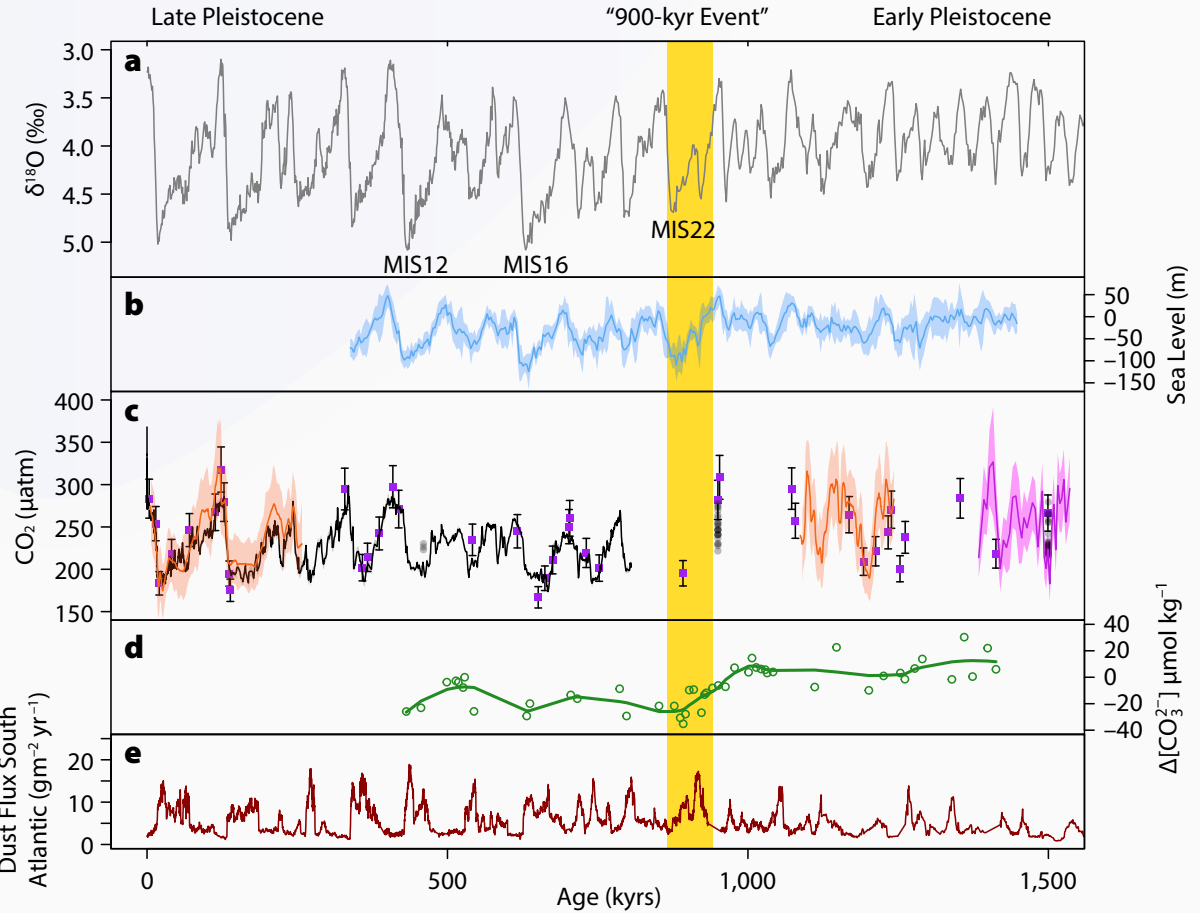

FIGURE 1. A selection of records across the Mid-Pleistocene Transition: (a) Benthic oxygen isotope stack (Lisiecki and Raymo, 2005). (b) Ice volume as a proxy for sea level, derived from $\delta^{18} \mathrm{O}$ of seawater from benthic foraminifera (Ford and Raymo, 2020). The light blue is the 1 sigma error envelope from a Monte Carlo simulation. (c) Atmospheric $\mathrm{CO}_{2}$ reconstructions, where the black line is the Antarctic ice core record and gray dots are the Antarctic blue ice record. The colored records are from marine sediment reconstructions (Chalk et al., 2017, and references within). Error bars are 2 sigma. (d) Carbonate ion records derived from foraminiferal trace element (B/Ca) (Farmer et al., 2019, and references within). (e) Southern Hemisphere iron dust based on analysis of marine sediments from Ocean Drilling Program Site 1090, located in the Atlantic sector of the subantarctic (Martínez-Garcia et al., 2011). Marine Isotope Stages (MIS) discussed in text are annotated, and the yellow bar highlights the $900 \mathrm{kyr}$ event. 
the strong glacial periods of the Late Pleistocene emerged, and after MIS 12, glacial-to-interglacial atmospheric $\mathrm{CO}_{2}$ ranged from $\sim 200 \mu$ atm to $280 \mu$ atm.

The role of $\mathrm{CO}_{2}$ as a driving mechanism for the MPT is debated, largely due to the absence of a continuous highresolution record over the transition. Within the next few years, ice drilling in Antarctica may yield some of Earth's oldest ice, with potential for recovering a continuous record of ancient atmospheric composition back to 1.5 million years ago (Dahl-Jensen, 2018). Nevertheless, existing high-resolution atmospheric $\mathrm{CO}_{2}$ snapshots before, during, and after the MPT suggest that a combination of ocean and ice sheet dynamics controls atmospheric $\mathrm{CO}_{2}$ cycles (e.g., Chalk et al., 2017).

Ocean dynamics played an increasingly important role in sequestering carbon in the deep ocean over the MPT, particularly during the glacial intervals. Neodymium isotopes and benthic foraminifera $\delta^{13} \mathrm{C}$, which are used as water mass tracers, show that intermediate- to deep-ocean circulation reorganized between MIS 25 and MIS 21 (Pena and Goldstein, 2014; Ford et al., 2016). Prior to the MPT, deep water formed in the polar north extended toward southern subpolar latitudes during glacial and interglacial periods. During the $900 \mathrm{kyr}$ event, southern-sourced deep water flooded the Atlantic, and its spatial range continued to be extensive during subsequent glacial intervals. This southern-sourced deep water is carbon-rich and has low carbonate ion values (e.g., more acidic, higher carbon content water; Farmer et al., 2019, and refer- ences within) and increased the deep ocean carbon reservoir. In addition to changing the geometry of major water masses, enhanced biological production changed the carbon content of the water subducting into the ocean's interior from the Southern Ocean, effectively sequestering more carbon in the global deep ocean. During the early stages of the MPT, the amount of iron-bearing dust supplied to the Southern Ocean began to increase (Figure 1), particularly during ice ages (Martínez-Garcia et al., 2011). This iron fertilized the Southern Ocean, increased biological productivity and biological pump efficiency, and contributed to the drawdown of $\mathrm{CO}_{2}$ (Chalk et al., 2017).

The triggers for these alterations in Southern Ocean circulation and biological dynamics remain unknown. A Southern Hemisphere insolation minimum around the $900 \mathrm{kyr}$ event points toward an Antarctic trigger that allowed sea ice to expand. Raymo et al. (2006) hypothesized that Antarctica's ice sheets transformed from terrestrial-based to marinebased at this time, though there is little physical evidence to support this. Changes in sea ice and ice sheet margins would have altered the freshwater balance of the Southern Ocean, strengthened water-column stratification, and contributed to sequestration of carbon into the ocean's interior (Hasenfratz et al., 2019).

Deciphering when, where, and how much ice volume growth occurred over the MPT from benthic $\delta^{18} \mathrm{O}$ records is difficult. An individual record reflects the regional signal from
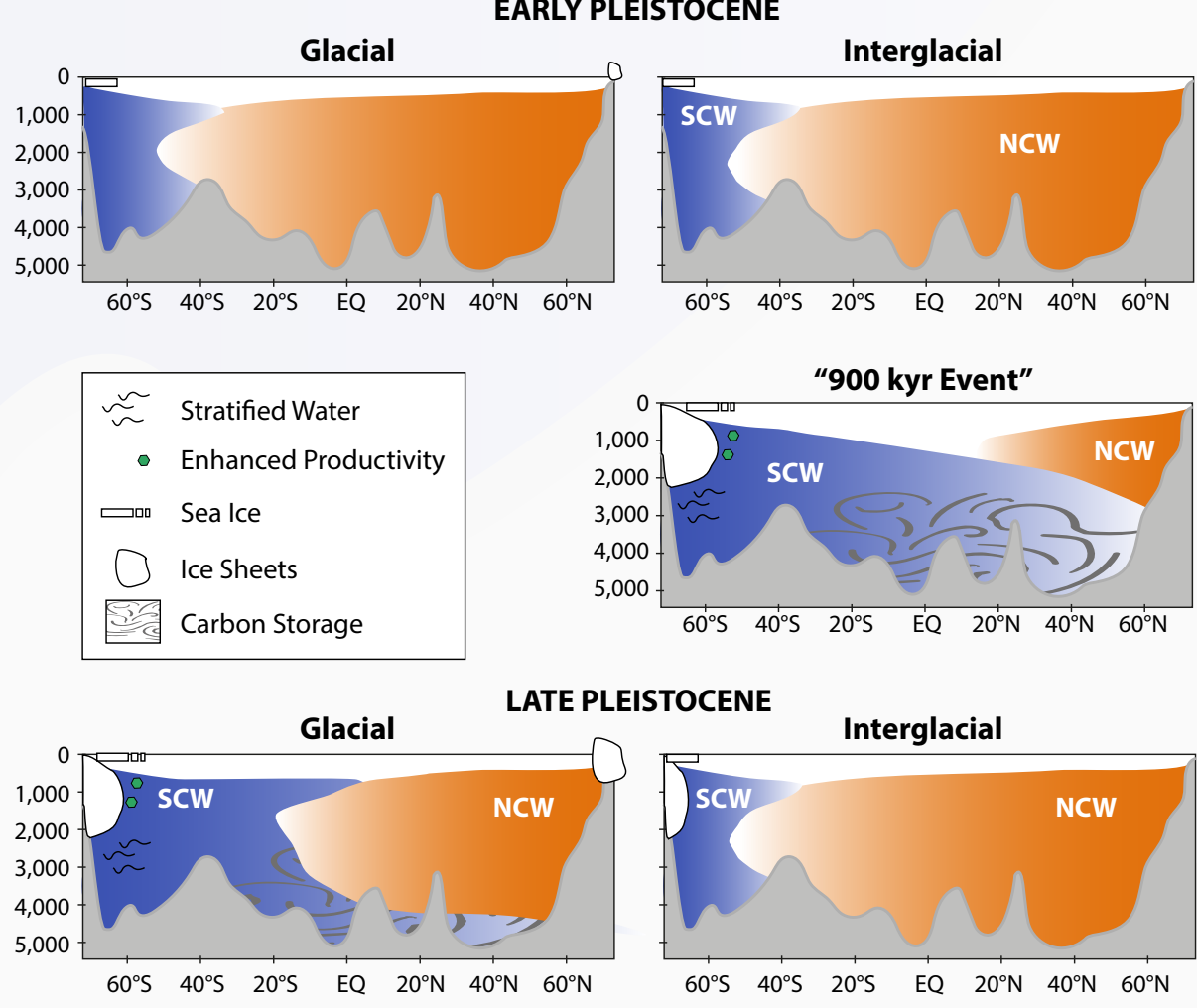

FIGURE 2. Schematic of biological productivity, carbon storage, ocean circulation, sea ice, and ice volume changes over the Mid-Pleistocene Transition derived from data displayed in Figure 1. $\mathrm{SCW}$ is southern component water, which is carbon-rich. NCW is northern component water. The $900 \mathrm{kyr}$ event represents a large reorganization of Southern Hemisphere processes. SCW and NCW are derived from $\mathrm{Nd}$ and $\delta^{13} \mathrm{C}$ records. 
where deep waters are formed (temperature and evaporation and precipitation processes that are imprinted in the $\delta^{18} \mathrm{O}$ of seawater), the circulation history of the water mass, and the global signal of both temperature and ice volume. Lisiecki and Raymo's (2005) original "LRO4 stack" (updated by Ahn et al., 2017) was revolutionary because these regional imprints were largely "averaged out," allowing them to create a global picture of temperature and ice volume over the last few million years (Figure 1). The question of where ice volume increased can only be inferred, even in a benthic stack.

Isolating $\delta^{18} \mathrm{O}$ of seawater is crucial for reconstructing changes in global ice volume over the MPT. The $\delta^{18} \mathrm{O}$ of benthic foraminifera calcite reflects both the temperature and $\delta^{18} \mathrm{O}$ of seawater in which the calcite formed. The magnesiumto-calcium ratio of benthic foraminifera calcite can be used to independently constrain temperature so that the $\delta^{18} \mathrm{O}$ of seawater can be teased apart. Although early interpretations from individual sediment cores were complicated by changes in ocean circulation, a recent stack of $\delta^{18} \mathrm{O}$ of seawater that includes North Atlantic, South Pacific, and North Pacific sites aims to construct a global picture of ice volume change (Ford and Raymo, 2020). It shows that ice volume grew during both MIS 22 and MIS 16 (Figure 1), though we don't know the precise location of this ice. Given the Southern Hemisphere insolation minimum during the $900 \mathrm{kyr}$ event, ice volume growth likely occurred in Antarctica during MIS 22 and consequently increased the sensitivity to the $100 \mathrm{kyr}$ cycle through hemispheric phase locking (Raymo and Huybers, 2008). Ice volume growth during MIS 16 likely had Northern Hemisphere origins, possibly related to Laurentian regolith removal and ice sheet stability (Clark and Pollard, 1998), and this growth completed the transition.

The MPT is a prime example of a gradual climate transition whereby small, additive changes in Earth's internal climate dynamics can force a large response, and the transition occurs with relatively minor changes to average $\mathrm{CO}_{2}$ levels (less than 20 year's average at current rates of anthropogenic emissions) and with no apparent changes to the structure of orbital parameters that have governed much of Cenozoic climate change. Studying exactly how these changes were triggered and how they interact with one another is going to be crucial as we enter the next phase of human-caused climate change.

\section{REFERENCES}

Ahn, S., D. Khider, L.E. Lisiecki, and C.E. Lawrence. 2017. A probabilistic Pliocene-Pleistocene stack of benthic $\delta^{18} \mathrm{O}$ using a profile hidden Markov model. Dynamics and Statistics of the Climate System 2:91-116, https://doi.org/10.1093/climsys/dzx002.

Chalk, T.B., M.P. Hain, G.L. Foster, E.J. Rohling, P.F. Sexton, M.P.S. Badger, S.G. Cherry, A.P. Hasenfratz, G.H. Haug, S.L. Jaccard, and others. 2017. Causes of ice age intensification across the Mid-Pleistocene Transition. Proceedings of the National Academy of Sciences of the United States of America 123, 201702143, http://doi.org/10.1073/pnas.1702143114.

Clark, P.U., and D. Pollard. 1998. Origin of the Middle Pleistocene Transition by ice sheet erosion of regolith. Paleoceanography and Paleoclimatology 13:1-9, https://doi.org/10.1029/97PA02660.

Dahl-Jensen, D. 2018. Drilling for the oldest ice. Nature Geoscience 11:703-704, https://doi.org/10.1038/s41561-018-0241-2.
Farmer, J.R., B. Hönisch, L.L. Haynes, D. Kroon, S. Jung, H.L. Ford, M.E. Raymo, M. Jaume-Seguí, D.B. Bell, S.L. Goldstein, and others. 2019. Deep Atlantic Ocean carbon storage and the rise of 100,000-year glacial cycles. Nature Geoscience 12:355-360, https://doi.org/10.1038/s41561-019-0334-6.

Ford, H.L., S.M. Sosdian, Y. Rosenthal, and M.E. Raymo. 2016. Gradual and abrupt changes during the Mid-Pleistocene Transition. Quaternary Science Reviews 148(C):222-233, https://doi.org/10.1016/j.quascirev.2016.07.005.

Ford, H.L., and M.E. Raymo. 2020. Regional and global signals in seawater $\delta^{18} \mathrm{O}$ records across the mid-Pleistocene transition. Geology 48(2):113-117, https://doi.org/10.1130/G46546.1.

Hasenfratz, A.P., S.L. Jaccard, A. Martínez-García, D.M. Sigman, D.A. Hodell, D. Vance, S.M. Bernasconi, H.F. Kleiven, F.A. Haumann, and G.H. Haug. 2019 The residence time of Southern Ocean surface waters and the 100,000-year ice age cycle. Science 363(6431):1,080-1,084, https://doi.org/10.1126/science. aat7067.

Lisiecki, L.E., and M.E. Raymo. 2005. A Pliocene-Pleistocene stack of 57 globally distributed benthic $\delta^{18} \mathrm{O}$ records. Paleoceanography and Paleoclimatology 20(1), https://doi.org/10.1029/2004PA001071.

Martínez-Garcia, A., A. Rosell-Melé, S.L. Jaccard, W. Geibert, D.M. Sigman, and G.H. Haug. 2011. Southern Ocean dust-climate coupling over the past four million years. Nature 476:312-315, https://doi.org/10.1038/nature10310.

Pena, L.D., and S.L. Goldstein. 2014. Thermohaline circulation crisis and impacts during the mid-Pleistocene transition. Science 345(6194):318-322, https://doi.org/10.1126/science.1249770.

Raymo, M.E., L.E. Lisiecki, and K.H. Nisancioglu. 2006. Plio-Pleistocene ice volume, Antarctic climate, and the global $\delta^{18} \mathrm{O}$ record. Science 313(5786):492-495, https://doi.org/10.1126/science.1123296.

Raymo, M.E., and P. Huybers. 2008. Unlocking the mysteries of the ice ages. Nature 451:284-285, https://doi.org/10.1038/nature06589.

Yan, Y., M.L. Bender, E.J. Brook, H.M. Clifford, P.C. Kemeny, A.V. Kurbatov, S. Mackay, P.A. Mayewski, J. Ng, J.P. Severinghaus, and J.A. Higgins. 2019. Two-million-year-old snapshots of atmospheric gases from Antarctic ice. Nature 574:663-666, https://doi.org/10.1038/s41586-019-1692-3.

\section{ACKNOWLEDGMENTS}

We are grateful to members of the PAGES Working Group on Quaternary Interglacials (QUIGS), and in particular participants of the workshop on Interglacials of the $41 \mathrm{kyr}$ world and the Mid-Pleistocene Transition, for stimulating discussions. Ford is supported by the Natural Environment Research Council (NE/N015045/1).

\section{AUTHORS}

Heather L. Ford (h.ford@qmul.ac.uk) is Lecturer in Environmental Science, Queen Mary University of London, London, UK. Thomas B. Chalk (t.chalk@noc. soton.ac.uk) is Postdoctoral Research Fellow, National Oceanography Centre, University of Southampton, Southampton, UK. 